\title{
The combined microscopic-endoscopic technique for radical resection of cerebellopontine angle tumors
}

\author{
Mohammad Abolfotoh, MD, PhD,,2 Wenya Linda Bi, MD, PhD, ${ }^{1}$ Chang-Ki Hong, MD, 1,3 \\ Kaith K. Almefty, MD, ${ }^{1,4}$ Abraham Boskovitz, MD, ${ }^{1}$ lan F. Dunn, MD, ${ }^{1}$ and Ossama AI-Mefty, MD1 \\ 'Department of Neurosurgery, Harvard Medical School, Brigham and Women's Hospital, Boston, Massachusetts; ${ }^{2}$ Department \\ of Neurosurgery, Ain Shams University, Cairo, Egypt; ${ }^{3}$ Department of Neurosurgery, Gangnam Severance Hospital, Yonsei \\ University, College of Medicine, Seoul, Korea; and 'Division of Neurological Surgery, Barrow Neurological Institute, Phoenix, \\ Arizona
}

OBJECT The combined microscopic and endoscopic technique has shown significant advantages in the management of various lesions through different approaches. Endoscopic-assisted techniques have frequently been applied to cerebellopontine angle (CPA) surgery in the context of minimally invasive craniotomies. In this paper the authors report on the use of the endoscope in the CPA as a tool to increase the extent of resection, minimize complications, and preserve the function of the delicate CPA structures. They also describe a technique of the simultaneous use of the microscope and endoscope in the CPA and dissection of CPA tumors under tandem endoscopic and microscopic vision to overcome the shortcomings of introducing the endoscope alone in the CPA. The reliability of using the microscope alone in dissecting CPA tumors is evaluated, as is the effectiveness of the combined technique in increasing the resectability of various types of CPA tumors.

METHODS The authors conducted a retrospective analysis of 50 patients who underwent combined microscopicendoscopic resection of CPA tumors by the senior author over a period of 3 years (February 2011 to February 2014) at Brigham and Women's Hospital, Harvard Medical School. The reliability of the extent of microscopic removal was evaluated with endoscopic exploration. Additional resection was performed with both microscopic and the combined microscopic-endoscopic technique. Endoscopically verified total resection was validated by intraoperative or postoperative MRI. The function of the cranial nerves was evaluated to assess the impact of the combined technique on their function.

RESULTS A tumor remnant was endoscopically identified in $69 \%$ of the 26 patients who were believed to have microscopic total resection. The utilization of the endoscopic visualization and dissection increased endoscopically verified total removal to 38 patients, and $82 \%$ of these patients had no sign of residual tumor on postoperative imaging. The technique was most effective with epidermoid tumors. There were a total of 17 new cranial nerve deficits in 10 patients. Preoperative fifth cranial nerve deficits improved in $52 \%$ and hearing improved in $29 \%$ of patients after surgery.

CONCLUSIONS This method provides simultaneous microscopic and endoscopic visualization and dissection techniques through skull-base approaches to CPA tumors. It overcomes some of the shortcomings of endoscopic-assisted surgery, further extends the surgical field, and increases the radicality of tumor resection with good functional outcomes. http://thejns.org/doi/abs10.3171/2014.10.JNS141465

KEY WORDS endoscopy; cerebellopontine angle; combined technique; radical resection; tumor; endoscopic skull-base surgery; skull-base approach

$\mathrm{T}$ HE acquisition of microscopic and endoscopic techniques in the surgical armamentarium has contributed enormously to the betterment of surgical outcome. The endoscopic-assisted technique has shown significant advantages in the management of various lesions through different approaches. ${ }^{2,3,26}$ Endoscopic techniques for cer- ebellopontine angle (CPA) surgery have been well studied and applied to tumor resection, vascular decompression, and aneurysm surgery. $5,8,10,17-19,22,23,28,32,34-36,39,40,42$ The advantages have been emphasized in the context of minimally invasive craniotomies, ${ }^{4,13,15,31}$ increasing visualization of hidden anatomy, and inspecting around corners. . $^{6,14,23,33,43 \text {, }}$

ABBREVIATIONS CPA = cerebellopontine angle; EVTR = endoscopically verified total resection. SUBMITTED June 27, 2014. ACCEPTED October 20, 2014.

INCLUDE WHEN CITING Published online April 24, 2015; DOI: 10.3171/2014.10.JNS141465.

DISCLOSURE The authors report no conflict of interest concerning the materials or methods used in this study or the findings specified in this paper. 
46,47 The shortcomings of endoscopic-assisted surgery in the CPA have also been well described. The inability of the endoscope to visualize structures proximal to the working space, a problem created by the crowded nature of the posterior fossa and the narrow corridor between critical neurovascular structures, places these structures at significant risk. In addition, maneuverability and the ability to conduct precise microdissection are limited in the space provided through traditional or minimally invasive craniotomies. This confinement results in "sword fighting" between competing instruments and the surgeons' hands in a small surgical window..$^{29}$ In this paper we report on the use of a combined microscopic-endoscopic surgical technique to maximize the degree of tumor resection, and we evaluate its effectiveness in addressing various tumors (meningiomas, epidermoids, schwannomas, and chordomas). This technique combines microscopic and endoscopic visualization and resection in skull-base approaches to overcome the hindrances of endoscopic-assisted surgery in the CPA and expand the degree of tumor resection.

\section{Methods \\ Data Collection}

We conducted a retrospective analysis of 50 patients with various tumors located in or involving the CPA, operated on by the senior author (O.A.M.) over a period of 3 years (February 2011 to February 2014) at Brigham and Women's Hospital, Harvard Medical School. These patients were operated on through various skull-base approaches (Table 1). The endoscope was used for the purpose of extending the approach, discovering hidden pieces of tumors, preserving neural structures, dissecting and removing tumors with the endoscopic technique, and confirming total removal.

The extent of microscopic resection was categorized into 3 groups based on operative reports and the surgeon's intraoperative impression: subtotal resection, near-total resection, and microscopic total resection. The findings of hidden tumor and involved dura or bone further visualized by the endoscope were recorded. Endoscopically verified total resection (EVTR), whether through additional resection or not, was compared with the postoperative MRI findings for each case. Surgical outcomes and complications were also analyzed.

Cranial nerve function was assessed prior to and immediately after surgery and at each follow-up visit. The results of formal audiograms, neuroophthalmological examinations, and swallowing assessments were obtained in

TABLE 1. Skull-base approaches used for 50 posterior fossa lesions

\begin{tabular}{lc}
\hline \multicolumn{1}{c}{ Approach } & No. of Cases \\
\hline Transmastoid retrosigmoid & 23 \\
\hline Transcondylar & 10 \\
\hline Anterior petrosal & 9 \\
\hline Posterior petrosal & 4 \\
\hline Cranioorbital zygomatic & 3 \\
\hline Total petrosectomy & 1 \\
\hline
\end{tabular}

patients with suspected deficits of hearing, vision, and the lower cranial nerves.

\section{Operative Technique for Combined Microscopic-Endoscopic CPA Surgery}

The room setup is arranged so that both surgeon and assistant have direct vision of high-definition monitors that display both the endoscopic and microscopic view (Fig. 1A, Video 1).

VIDEO 1. Clip showing the surgeon position, room setup, and monitors used in the technique of this study. Note that the two monitors display the microscopic and endoscopic views during dissection.

Copyright Ossama Al-Mefty. Published with permission. Click here

to view with Media Player. Click here to view with Quicktime.

A 4-mm neuroendoscope with high-definition video is used with $0^{\circ}, 30^{\circ}$, and $70^{\circ}$ lenses. Importantly, the endoscope should have a right-angled grip to keep the assistant's hand out of the microscopic view. The endoscope is introduced under both microscopic and endoscopic visualization to prevent injury to CPA structures. The microscope is kept in place to help direct the endoscope during removal, reintroduction, and instrument exchanges during dissection. Both endoscopic and microscopic views are simultaneously displayed on multiple high-definition screens (analogous to picture-in-picture; ${ }^{41}$ Fig. 1B) clearly visible to the entire surgical team, i.e., the surgeon, assistant surgeon, and assisting nurses. Dissection is performed utilizing either the microscopic or endoscopic view, whichever is optimal. We use the "freehand" technique, in which the assistant holds and directs the endoscope while the surgeon performs the dissection with 2 hands (Fig. 1C). Continuous neuronavigation is provided

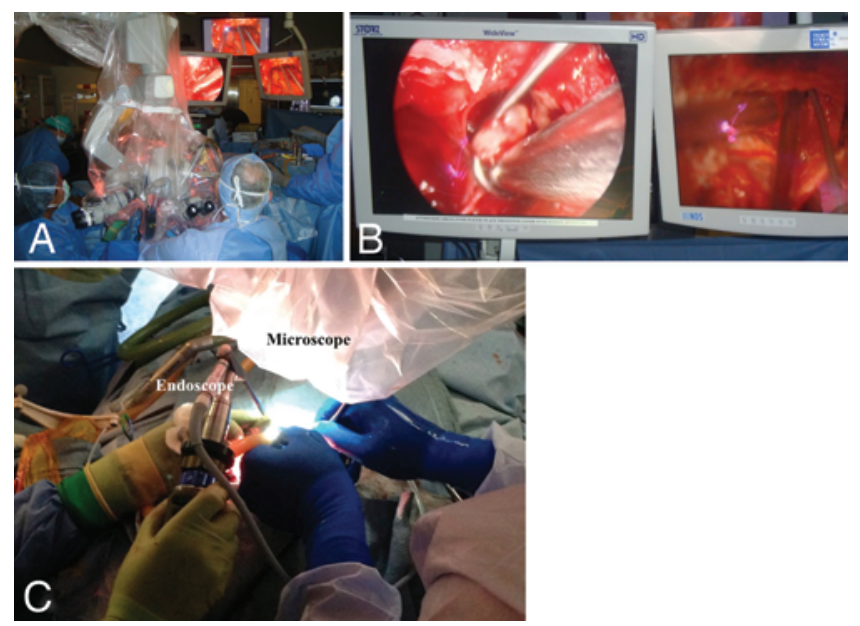

FIG. 1. Intraoperative photographs. A: The setup of the operating room for the combined microscopic-endoscopic technique used to approach the CPA. The endoscope is introduced with simultaneous displays on high-definition screens showing both the microscopic and endoscopic views. The primary surgeon conducts the dissection while looking at the endoscope screen; the assisting surgeon navigates the endoscope while at the same time observing the microscope view. B: The two high-definition screens that display the microscopic (left) and endoscopic (right) views in direct sight of the surgical team. C: The hands of the dissecting surgeon (blue gloves) and the endoscopic driver (white gloves) easily maneuvering in the space provided by the skull-base approach. Figure is available in color online only. 
by calibrating the microscope's focal point as the pointer. Neurophysiological monitoring of all potentially involved cranial nerves is used. The transmastoid approach, as previously described, ${ }^{1}$ is most commonly used and all intradural work is begun with microscopic dissection until satisfactory resection is achieved. The endoscope is then introduced, most commonly with a $30^{\circ}$ angled lens (occasionally a $0^{\circ}$ or $70^{\circ}$ lens), for extensive exploration of the $\mathrm{CPA}$ and beyond. If residual tumor is identified, further resection is pursued (Fig. 2, Videos 2 and 3).

VIDEO 2. Clip showing resection from a transmastoid retrosigmoid approach of the case presented in Fig. 7. In this clip the combined microscopic-endoscopic removal of a CPA meningioma is shown. The primary bulk of the tumor is resected with the microscope. Additional tumor is identified and removed with the combined microscopic-endoscopic technique. Finally, invaded dura of the suprameatal tubercle and petrous apex are drilled entirely using the endoscopic view with the second surgeon guiding the endoscope. Copyright Ossama Al-Mefty. Published with permission. Click here to view with Media Player. Click here to view with Quicktime.

VIDEO 3. Clip showing the transmastoid retrosigmoid approach for the resection of an epidermoid with the combined microscopicendoscopic technique. The endoscope is used to explore the microscopic field following resection and removal of tumor from the microscopic blind spots in the CPA around the cranial nerves. The endoscope is then used to pursue additional tumor in the middle fossa through the incisura. Note the remarkable visualization of the optic apparatus, third cranial nerve, medial temporal lobe, and posterior cerebral artery. Copyright Ossama Al-Mefty. Published with permission. Click here to view with Media Player. Click here to view with Quicktime.

\section{Results}

The study participants comprised 30 female and 20 male patients with a mean age of 46 years (range 17-76 years, median 49 years). The types of tumors and their primary locations are summarized in Fig. 3, and their secondary extensions are detailed in Fig. 4. The mean followup duration was 18 months (range 3-40 months).

\section{Extent of Resection}

In 26 patients, resection was considered total with the use of the microscope only (the extent of removal after microscopic dissection), but 18 (69\%) of these 26 patients had a "false negative" as residual tumor was found when the endoscope was used. Twenty-four patients were suspected to have residual tumor after microscopic dissection (subtotal and near-total resection), and all (100\%) were confirmed to have residual tumor after the endoscope was introduced. The extent of resection with the microscope, and after endoscopic exploration and pursuing further resection for the whole study, is summarized in Fig. 5; the reliability of microscopic resection as judged by the endoscope in each pathology and location is summarized in Fig. 6.

Independent of the degree of presumed microscopic resection, the endoscope visualized tumor remnants in 42 patients; further dissection of these endoscopically visualized residuals was attempted in 34 patients using either the combined microscope-endoscope technique (15 patients), the microscope (7 patients), or both (12 patients). In 30 $(88 \%)$ of these 34 patients, the residual tumor seen through the endoscope was completely resected as confirmed by postoperative MRI, thus increasing the extent of resection to EVTR in 38 patients. In 4 patients, EVTR was not achieved despite the attempt.

\section{Correlation With Postoperative MRI}

We compared the findings on immediate postoperative and follow-up MRI with the intraoperative endoscopic findings. In the 38 patients with EVTR in this series, MRI confirmed the absence of residual tumor in $31(82 \%)$. The immediate postoperative MRI showed small residual tumor $(<5 \mathrm{~mm}$ in any diameter) in 2 patients. In 1 patient with a petroclival meningioma, the MRI showed a small residual mass in Meckel's cave. In the other case, enhancement concerning for residual vestibular schwannoma was observed along the brainstem but was decreased in size on follow-up MRI. Five patients had postoperative enhancement in the tumor bed, with stable imaging on 1-year follow-up MRI. One patient experienced recurrence of an aggressive petroclival meningioma; this was the only patient to undergo a second surgery, 2 years later. At that time, this patient had EVTR and the postoperative MRI was clear. Two other patients with known subtotal resection had regrowth of residual tumor.

\section{Cranial Nerve Function}

Table 2 details the cranial nerve functions preoperatively and at follow-up. The most frequent preoperative cranial nerve deficits encountered in this cohort were the loss of facial sensation and ipsilateral hearing. After resection, oculomotor palsy, trigeminal impairment, hearing
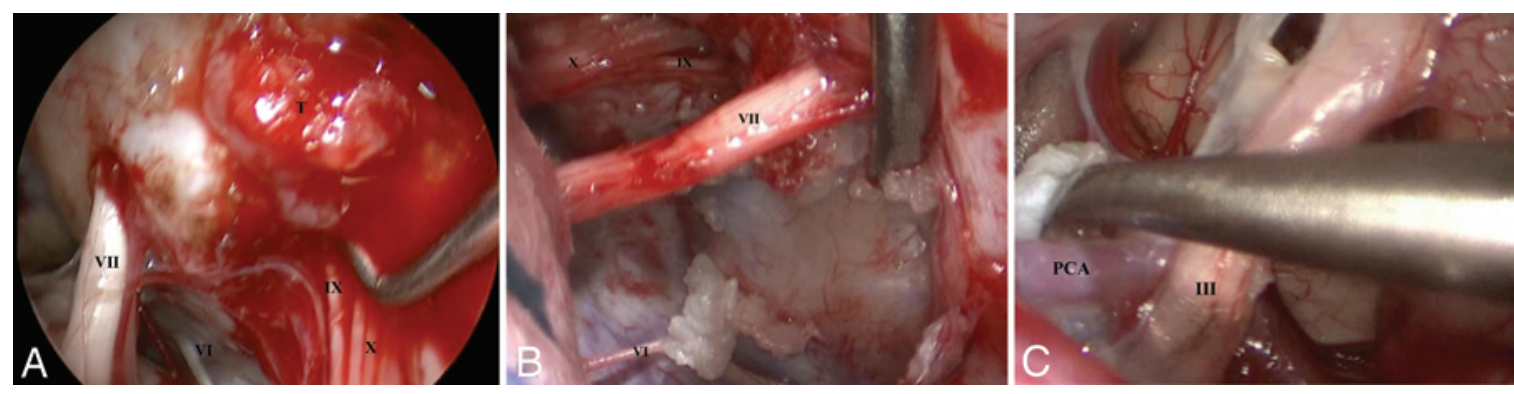

FIG. 2. Intraoperative photographs demonstrating the endoscopic dissection of hidden tumor pieces that extended into additional compartments. A: A piece of the meningioma $(T)$ is hidden inside the jugular foramen. Cranial nerves $\mathrm{VI}, \mathrm{VII}, \mathrm{IX}$, and $\mathrm{X}$ are shown. B: Photograph showing hidden epidermoid tumor under the respective cranial nerves. C: Endoscopic removal of epidermoid tumor that extended through the incisura. PCA = posterior cerebral artery; III = cranial nerve III. Figure is available in color online only. 


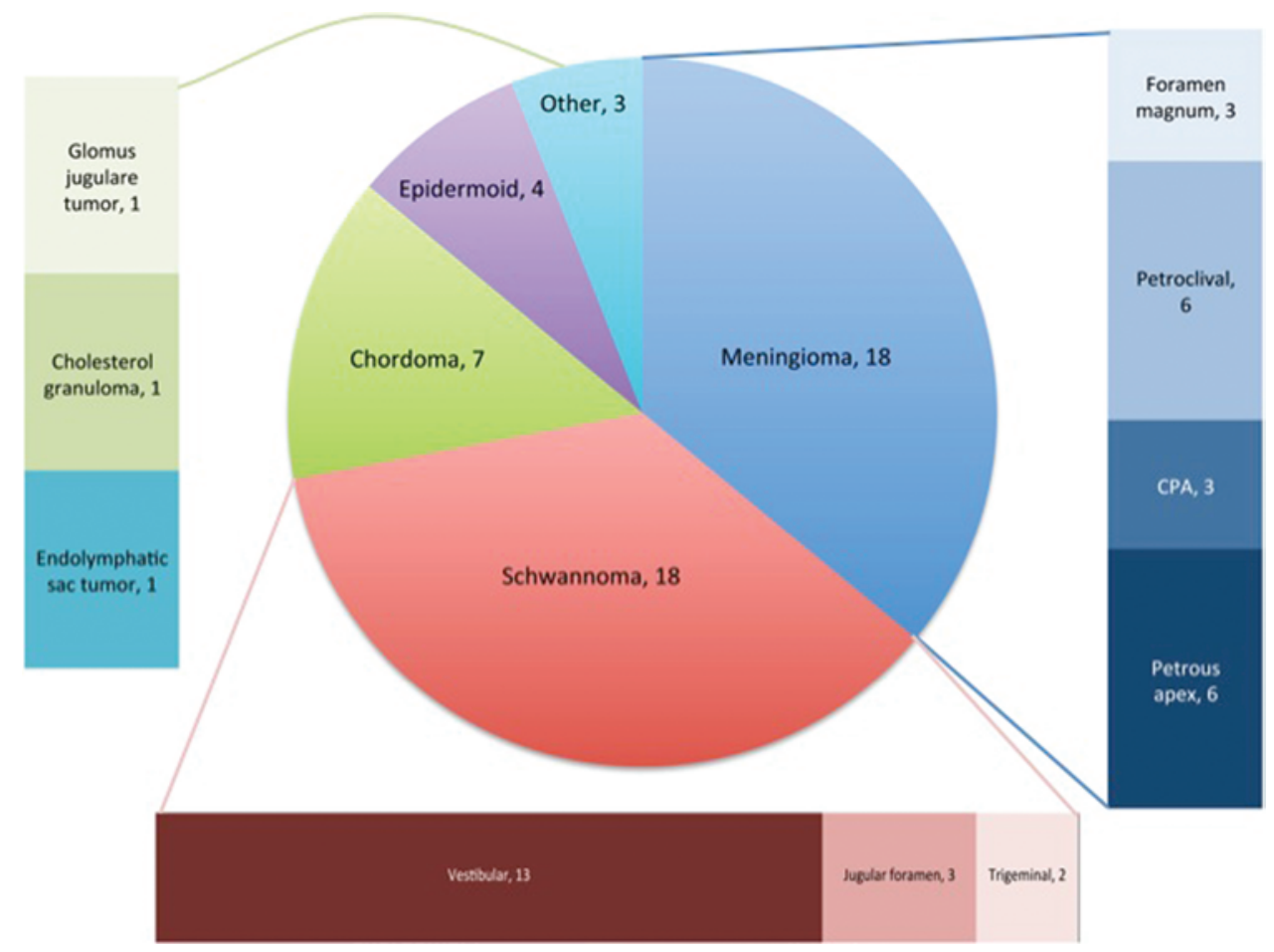

FIG. 3. A bar-in-pie chart demonstrating the diagnosis and primary location of the 50 posterior fossa lesions incorporated in this study. Figure is available in color online only.

loss, lower cranial nerve dysfunction, and tongue deviation improved in a subset of patients. Notably, $83 \%$ of patients with preoperative swallowing difficulties improved after surgery, while $52 \%$ of patients with preoperative facial numbness or paresthesias experienced full resolution of symptoms. Hearing function improved in $29 \%$ of patients after surgery. In this series, 5 patients developed new facial nerve deficits after tumor resection, 2 developed new trochlear nerve palsies, 2 developed new horizontal diplopia, and 3 patients had new dysphagia. There were 18 permanent cranial nerves deficits; considering that cranial nerves III-XII are at risk in these 50 patients, that represents a $4 \%$ odds risk of developing a cranial nerve deficit.

\section{Discussion}

The endoscope has been used in CPA surgery in two primary ways: 1) endoscopic controlled, when the endoscope is the only source of visualization and instruments are passed alongside the endoscope; and 2) endoscopic assisted, when the endoscope is used as a supplementary visualization tool to assist in primarily microscopic procedures. The advantages of the use of the endoscope have been emphasized in the context of minimally invasive surgery, $4,13,15,31$ with the goal of decreasing morbidity by minimizing soft-tissue dissection and decreasing the size of the craniotomy. In this study, we emphasize the endoscope's utility in achieving improved results in skull-base approaches, as a tool capable of expanding the surgical field, and for increasing the resectability of challenging lesions in the posterior fossa. Long-term patient morbidity is best reduced through maximal safe tumor resection rather than decreasing the size of the craniotomy. Used in this manner, the endoscope demonstrated utility in 3 important aspects: 1) extending the surgical field into additional intracranial compartments; 2) allowing for visualization and resection of residual tumor not adequately visualized with the microscope; and 3) improving the prediction of the extent of resection. In addition, the technique described here overcomes some of the previously detailed shortcomings of the use of the endoscope in the CPA.

\section{Advantages of the Endoscope}

Extending the Surgical Field

In the present series, the endoscope was useful for expanding the surgical field. In particular, through the tentorial incisura, the endoscope allows an extension of the microsurgical approach from the posterior fossa to the middle fossa, enabling the resection of tumor from the subchiasmatic cistern, Meckel's cave, and even across the midline. The view through the microscope in the CPA region is limited to the dorsal surface of the neurovascular structures, but the endoscope provides a vantage point ventral to these structures.

\section{Visualizing and Resecting Additional Tumor}

The utility of the endoscope in visualizing and resecting tumor in microscopic blind spots and around corners is well established. $6,7,14,23,33,43,46,47$ The endoscope, especially with angled lenses, allows visualization of a residual lesion in locations not well seen through the microscope. The microscope is inherently limited in its angles of observation because its focal trajectory begins outside the 


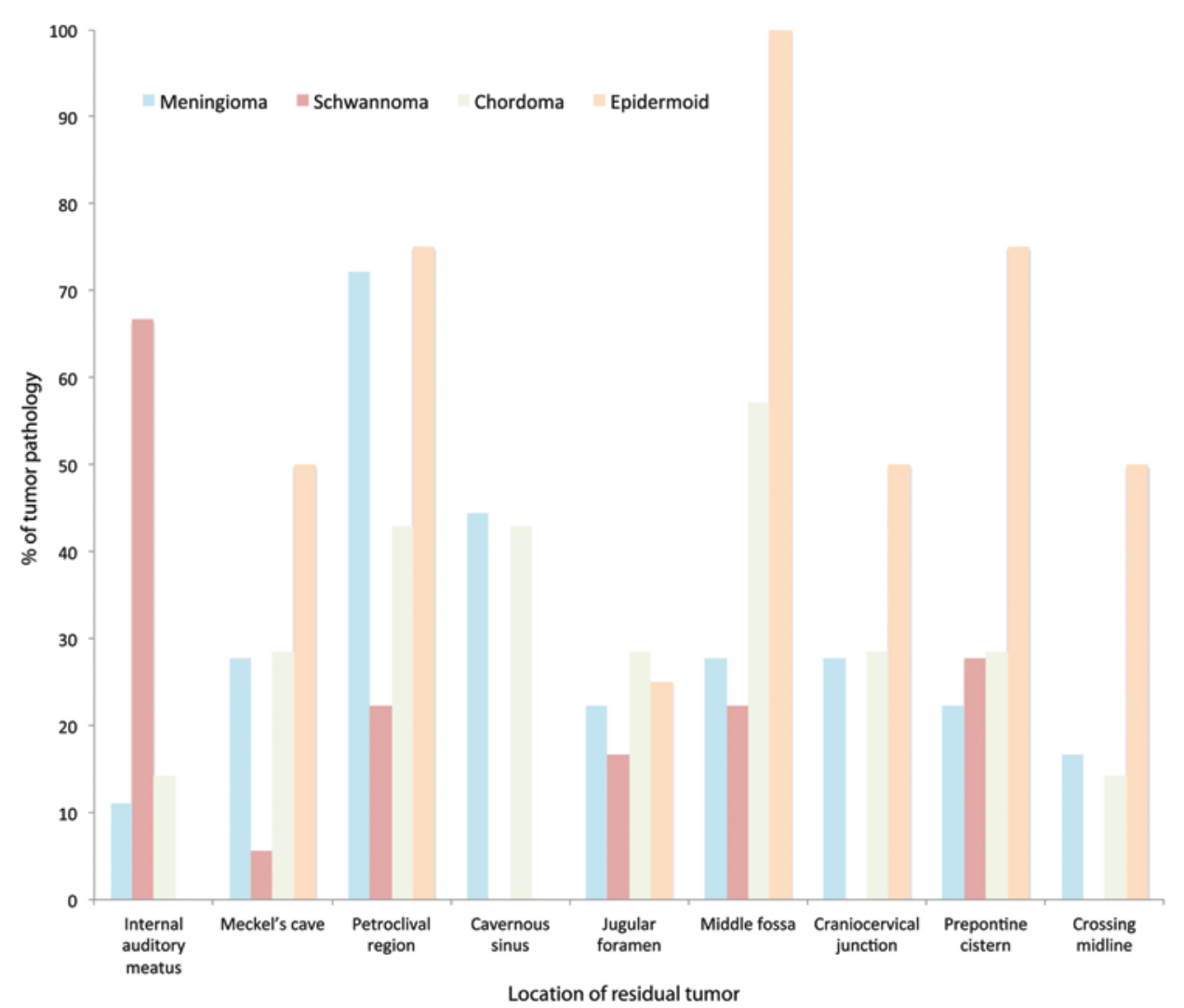

FIG. 4. A bar chart summarizing the frequency of secondary anatomical extensions from their primary location by tumor pathology. Note the high frequency of epidermoid tumors extending to additional skull-base compartments that are hidden from the traditional retrosigmoid microscopic view. Figure is available in color online only.

field. Because the critical neurovascular structures cannot be retracted, lesions can be hidden from the microscope's vantage point. The endoscope overcomes this shortcoming in two ways: 1) it obtains its vantage point from within the surgical field; and 2) the angled lenses allow visualization in a trajectory distinct from the working trajectory.

These microscopic blind spots are unique to each approach. For example, in the retrosigmoid approach, the microscope cannot visualize the anterior surface of the VII-X cranial nerves, the ventral surface of the trigeminal nerve, or inside the foramina or canals. The blind spots in the middle fossa approaches are the inferior and lateral aspects of the CPA and the CPA posterior to the internal auditory meatus.

In an anatomical review of the utility of the endoscope in the CPA with posterior approaches, Takemura and colleagues described superior visualization with the endoscope. ${ }^{43}$ They divided the CPA into 3 sections: superior, middle, and inferior. At the superior level, the endoscope provided improved views of the junction of the trigeminal nerve and the pons, the entrance into the porus of Meckel's cave, and the CPA's relationship with the superior cerebellar artery. At the middle level, visualization was improved at the root exit zone of the facial nerve from the brainstem. At the inferior level, the endoscope improved visualization of the medullary junction, the dural exit of the IX-XI cranial nerves, and the vasculature anterior to the lower cranial nerves. ${ }^{43}$ Ebner and colleagues emphasized the importance of using the endoscope and microscope as complementary modalities to provide more complete visualization of the CPA. Our study further emphasizes the endoscope's essential complementary role in identifying and allowing for the resection of remnant tumor in these locations. In addition, the closer vantage point, increased magnification, and improved illumination facilitate careful inspection of the dura and bone. In this series, use of the endoscope frequently identified infiltrated dura and bone, which appeared to be normal under microscopic visualization. ${ }^{12}$

\section{Improved Prediction of the Extent of Resection}

Our study highlighted the poor reliability of the microscope alone in evaluating the extent of resection intraoperatively. The endoscope improved the reliability of intraoperative inspection after tumor resection. In 26 patients, gross-total resection was believed to be achieved after microscopic dissection, but the endoscope identified additional tumor in 18 patients (69\%). Conversely, the endoscope was highly predictive of postoperative MRI findings. In the 38 patients in whom EVTR was achieved, the postoperative MRI showed clear evidence of residual tumor in only 2 patients. Five other patients had some postoperative enhancement along the tumor bed, which was stable 1 year postoperatively. These findings demonstrate the superiority of the endoscope in assessing the degree of resection in patients with extensive posterior fossa lesions. 


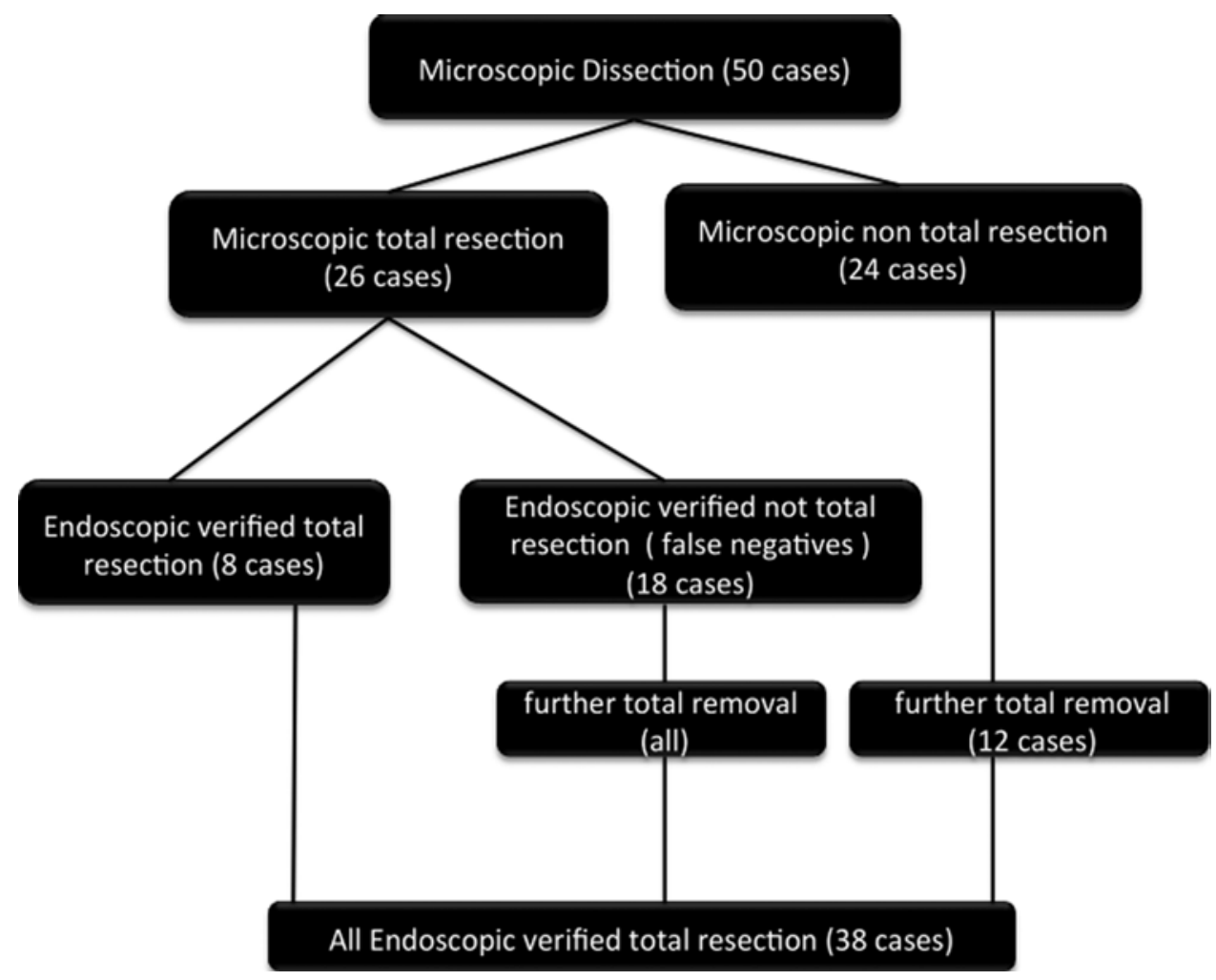

FIG. 5. Flowchart summarizing the extent of resection after initial microscopic dissection, the subsequent endoscopic findings, and the results of further dissection after introduction of the endoscope.

\section{Overcoming the Shortcomings of the Endoscope}

The crowded complex anatomy of the posterior fossa, and the lack of a flexible noneloquent corridor such as the nasal cavity, complicate the use of the endoscope in the CPA. A number of limitations with its use have been reported, particularly with the freehand technique described by de Divitiis and associates. ${ }^{11}$ These limitations include: 1) difficulty safely inserting and removing instruments, because the endoscope's field of view is distal to critical structures; 2) the endoscope's presence as a third instrument in a small surgical window, resulting in "sword fighting" between instruments and difficulty with performing microdissection. ${ }^{29}$ Our experience, however, shows that these issues with the endoscope are diminished, if not resolved, through the use of the extended retrosigmoid approach previously described. ${ }^{1}$

The broad surgical corridor provided by the extended retrosigmoid and other skull-base approaches used in this series easily allows 3 hands to remain in the field without combatting. In addition, the microscope remains in use simultaneously, and multiple monitors or "picture-in-picture" projection ${ }^{41}$ allows for both surgeons to see both the microscopic and endoscopic views. The microscopic view displays the broad surgical field and dorsal neurovascular structures, while the endoscopic view displays the details in the microscopic blind spots. The assistant is able to hold the endoscope in a dynamic freehand manner without risking injury to structures proximal to it. The operating surgeon can then efficiently insert and remove instruments without the cumbersome need to insert and remove the endoscope with each instrument change.
One major concern with the navigation of an endoscope in a limited corridor is the potential for additional injury to the cranial nerves, either through direct trauma or indirect thermal-related injury from the dual light sources. ${ }^{20,25}$ The additional visualization of residual tumor in the foramina and around neurovascular corners may prompt a more aggressive pursuit of total resection, which could also contribute to neural deficits. Despite these concerns, we documented improvements in cranial nerve function in a significant number of patients with preoperative deficits, especially with swallowing and facial sensation. Ten percent of patients without preoperative facial palsy had developed new facial nerve weakness at the time of the most recent follow-up evaluation, which is within the minimal expected range of resection risks for surgery in the CPA. ${ }^{24,40,43,44}$ The majority of patients with new postoperative facial deficits harbored vestibular schwannomas with an extension into the internal auditory canal, while 2 patients had large meningiomas.

Most distinct from the "minimally invasive" perspective, the broad surgical field provided by skull-base approaches allows the surgeon to expand the exposure and perform 2-handed microdissection under endoscopic visualization. In an endoscopic anatomical study of the CPA, Chaynes and colleagues concluded that craniotomies smaller than $10 \mathrm{~mm}$ did not allow for complete exploration of the CPA, and maneuverability was significantly limited. These hindrances were overcome with craniotomies of $15 \mathrm{~mm}$ or more. ${ }^{7}$ Ebner and associates emphasized that adjunctive use of the endoscope should not minimize the exposure obtained through the microsurgical approach. ${ }^{12}$ 


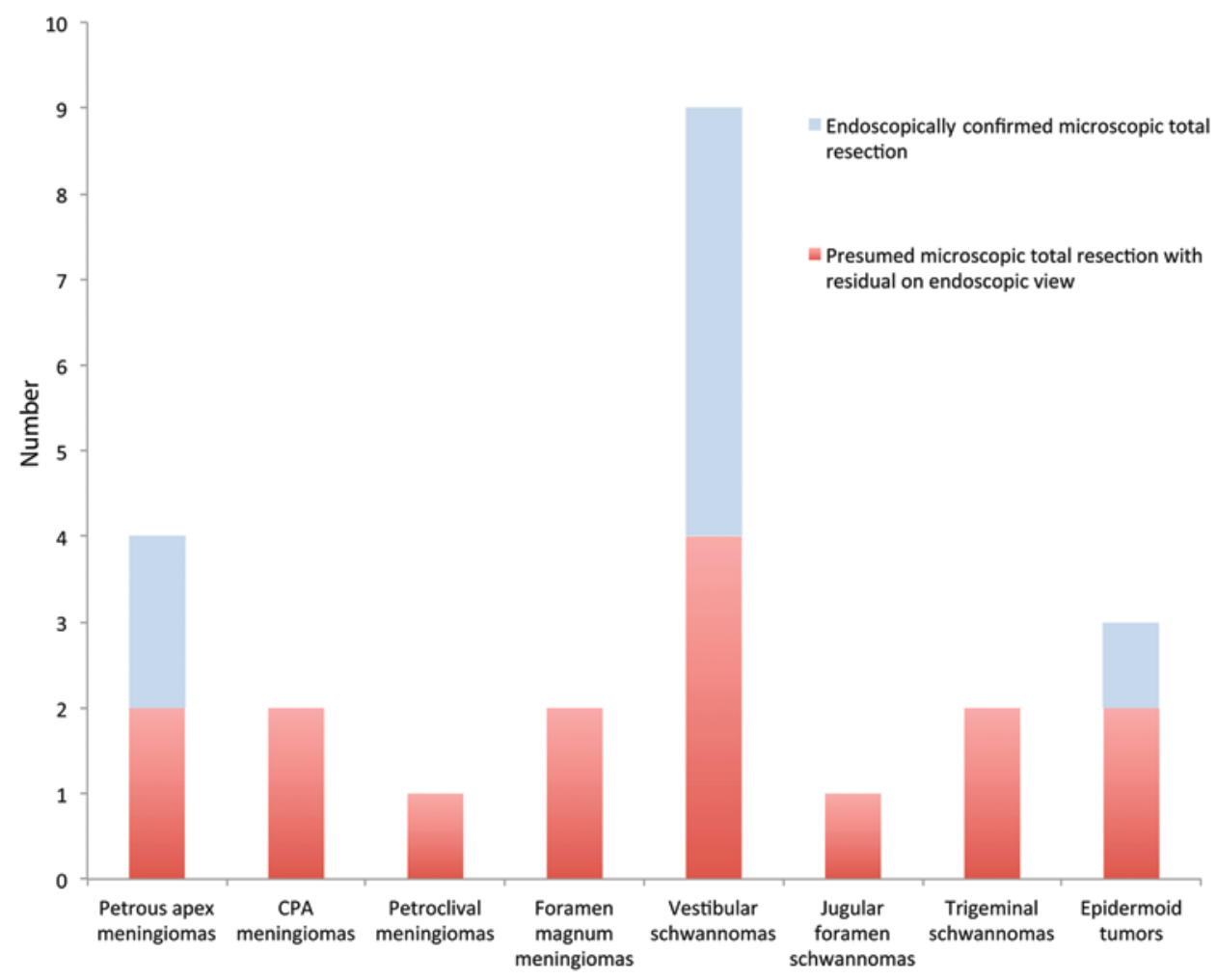

FIG. 6. A stacked bar chart demonstrating the reliability of the microscopic view in assessing the extent of resection and the frequency in which the endoscope either confirmed total resection (blue) or identified additional tumor not visualized with the microscope (red). Figure is available in color online only.

While we agree with these assessments, our technique goes even further and emphasizes the importance of adjunctive use of the endoscope in expanding the microsurgical approach, thus providing additional visualization and dissection capabilities through the same exposure rather than the same visualization through a smaller exposure.

\section{Application of the Technique to Specific Tumors}

Others have previously reported on the use of an endoscopic-assisted technique in the resection of meningiomas. ${ }^{39,47}$ Yuguang et al. ${ }^{47}$ included 1 meningioma in their series of $23 \mathrm{CPA}$ lesions and noted its utility in identifying residual tumor and protecting the cranial nerves. Schro- eder et al. ${ }^{39}$ reported the largest series of meningiomas resected with an endoscopic-assisted technique, 23 of which were in the CPA. In their study, the endoscopic view visualized tumor hidden from the microscopic view in $56 \%$ of cases and thus demonstrated the high utility of the endoscope in identifying hidden tumor.

Prudently, Schroeder et al..$^{39,40}$ note that movement of the endoscope within the CPA is dangerous and thus advocates for the use of an endoscope fixation arm. The use of the fixation arm is effective in preventing trauma to the neurovasculature of the CPA. However, it is limited by not providing visualization of the CPA during instrument exchanges and it does not allow for the dynamic vi-

TABLE 2. Number of cranial nerve deficits before and immediately after surgery and at last follow-up in the 50 patients with combined microscopic-endoscopic resection of CPA lesions

\begin{tabular}{|c|c|c|c|c|c|}
\hline \multirow{2}{*}{$\begin{array}{l}\text { Cranial } \\
\text { Nerve }\end{array}$} & \multirow[b]{2}{*}{ Preop Deficit } & \multicolumn{2}{|c|}{ Early Postop Deficits } & \multicolumn{2}{|c|}{ Postop Deficits on Latest Follow-Up } \\
\hline & & In Patients w/ Preop Deficits & In Patients w/o Preop Deficits & In Patients w/ Preop Deficits & In Patients w/o Preop Deficits \\
\hline III & 4 & 3 & 0 & 3 & 0 \\
\hline IV & 0 & 0 & 4 & 0 & 2 \\
\hline V & 21 & 12 & 4 & 10 & 3 \\
\hline VI & 8 & 8 & 2 & 6 & 2 \\
\hline VII & 5 & 5 & 7 & 4 & 5 \\
\hline VIII & 21 & 17 & 4 & 15 & 2 \\
\hline$|X-X|$ & 6 & 2 & 4 & 1 & 3 \\
\hline XII & 7 & 6 & 0 & 5 & 0 \\
\hline
\end{tabular}


sualization of the region as dissection proceeds. Dynamic visualization is of particular importance in endoscopic dissection because it helps to compensate for the loss of stereoscopic vision. Our technique resolves these two issues by providing a tandem endoscopic and microscopic view with a third hand guiding the endoscope under microscopic visualization.

The endoscope is useful in resecting meningiomas because it can identify and remove hidden tumor, especially superiorly and laterally beneath the tentorium, superior to the trigeminal nerve, and in the jugular foramen (Fig. 2A). In this series, the unique advantage of using the endoscope with meningiomas was identifying abnormal dura and bone devitalized by tumor, which was not possible with the microscope. Removal and coagulation of the dura, as well as the drilling of abnormal bone, was completed with the endoscope (Fig. 7, Video 2). The primary drawback of using the endoscope in meningioma surgery is the frequent need to clean the lens because of the bloody nature of the surgery and the accumulation of bone dust from drilling. For this reason, we recommend introducing the endoscope as late as possible in the course of microscopic dissection of meningiomas.

The use of the endoscope for schwannoma surgery has been frequently reported and is summarized in Table 3
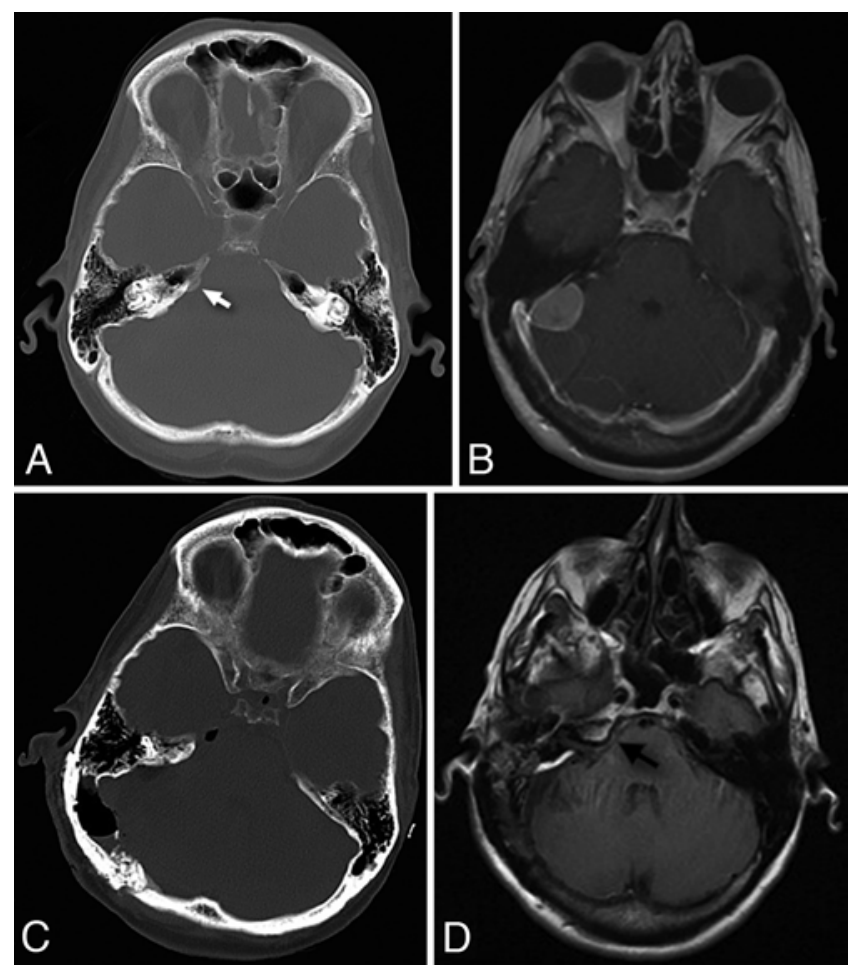

FIG. 7. Axial images for a patient with a CPA meningioma removed through the transmastoid retrosigmoid approach. In this case, the hyperostotic bone anterior to the facial nerve was drilled completely with the use of the endoscope. A: The preoperative CT scan with a bone window shows deep hyperostotic bones in the petrous apex (white arrow). B: The preoperative T2-weighted MR image with contrast shows the retromeatal soft-tissue part and the premeatal bony part of the tumor. C: The postoperative CT scan with a bone window shows the removal of the petrous apex. D: The postoperative MR image without contrast shows the fat plug of the opened air cells of the petrous apex (black arrow). with emphasis on the extent of resection, hearing preservation, and facial nerve function. This review of the literature demonstrated the remarkable utility of the endoscope in increasing the extent of resection and improving functional outcomes of the facial nerve. However, there was little evidence of improved hearing preservation with use of the endoscope. ${ }^{17}$ Our findings corroborate those of other studies that the endoscope is helpful in removing tumor at the canal fundus. We expect that it also improves hearing preservation by decreasing the amount of bone drilled in the posterior wall of the canal, thus decreasing the risk of injury to the superior and posterior semicircular canals. The microscopic view, on the other hand, requires wide drilling of the canal for visualization, and this can be reduced with the endoscope. The utilization of the endoscope was also helpful in improving hearing by preservation of the cochlear fibers at the lamina cribrosa.

Reports of the use of the endoscope in CPA epidermoid surgery are not uncommon..$^{9,11,37,38,40,45,48}$ Tuchman et al. ${ }^{45}$ most recently reported on the specific use of the endoscope in the removal of 9 CPA epidermoid tumors, 7 of them through a retrosigmoid approach, and 2 with a subtemporal approach. These investigators used an endoscopic-assisted technique with initial resection performed with the microscope and importantly report that additional tumor was identified with the endoscope in $85 \%$ of cases. They recommend a 2-surgeon, 4-hand technique rather than the use of a holder to provide a dynamic view of the operative field. Our findings and principles fully concur with their study. We do, however, emphasize the simultaneous use of the microscopic view with the endoscopic dissection to add protection to the proximal cranial nerves.

Zhang et al. ${ }^{48}$ reported on the use of the endoscope in 30 posterior fossa epidermoid cases in their broad review of 126 neuroendoscopic procedures. However, this early report focused on the use of the endoscope as a tool in neurosurgery and did not provide a detailed description of the endoscope's role in CPA epidermoid surgery. Schroeder et al. ${ }^{40}$ reported on 8 cases of CPA epidermoids; in 4 cases the tumor was removed microscopically with the use of the endoscope only for verification and not dissection. In the other 4 cases, a technique analogous to the previously mentioned meningioma series was utilized. In that series 5 cases were performed utilizing a retrosigmoid and 3 by a pterional approach, with small craniotomies. The endoscope revealed microscopically hidden tumor in all cases. However, total removal of the capsule was only achieved in 3 cases.

Safavi-Abbasi et al. ${ }^{38}$ reported a series of 11 patients in which the endoscope was used for inspection following microscopic resection in epidermoid surgery. They advocated against the use of the endoscope for tumor dissection in epidermoids, recommending it to be used solely for inspection.

Patients with epidermoid tumors may benefit the most from the endoscopic-assisted technique. Epidermoids tend to travel away from their primary location, often extending to the middle fossa, crossing the midline, and expanding in the posterior fossa cisterns (Fig. 4). The endoscope can extend the microscopic approach to follow the epidermoid debris into the middle fossa (Fig. 2C) and to the contralat- 
TABLE 3. Summary of the literature of endoscopic-assisted removal of posterior fossa lesions

\begin{tabular}{|c|c|c|c|c|c|}
\hline Authors \& Year & Pathology & Cases & Total Removal (\%) & Postop Hearing Status & Postop Facial Nerve Status \\
\hline King \& Wackym, 1999 & Schwannoma & 10 & $9(90)$ & $2 \mathrm{HL}$ & 1 facial palsy \\
\hline Magnan et al., 2002 & Schwannoma & 119 & $105 / 106(99)^{*}$ & $58 \mathrm{HP}$ & Facial nerve anatomically preserved in all cases \\
\hline Gerganov et al., 2005 & Schwannoma & 18 & $11(61)$ & $17 \mathrm{HL} \dagger$ & 4 facial palsy \\
\hline Göksu et al., 2005 & Schwannoma & 60 & $60(100)$ & $34 \mathrm{HL}$ & 19 facial palsy \\
\hline \multirow[t]{2}{*}{ Gerganov et al., 2010} & Schwannoma & 30 & $30(100)$ & Total NUH = 13 & $\mathrm{HB}>\mathrm{Il}$ in $9 \ddagger$ \\
\hline & Schwannoma & 50 & $49(98)$ & Total NUH = 24 & $\mathrm{HB}>\mathrm{II}$ in 27; 1 facial nerve has lost integrity $\ddagger$ \\
\hline Hori et al., 2010 & Schwannoma & 33 & $28(84)$ & $50 \%$ hearing preservation & 2 facial palsy \\
\hline Kumon et al., 2012 & Schwannoma & 28 & $14(50)$ & $50 \%$ hearing preservation & 2 facial palsy \\
\hline Chovanec et al., 2013 & Schwannoma & 39 & $39(100)$ & $\mathrm{HB}>\mathrm{II}$ in $16,14 \mathrm{HL}$ & No facial palsy \\
\hline lacoangeli et al., 2013 & Schwannoma & 10 & $8(80)$ & $\mathrm{HL}$ in 1 case & 2 facial palsy $\ddagger$ \\
\hline Schroeder et al., 2011 & Meningioma & 23 & $14(61)$ & $\mathrm{HL}$ in 2 cases & 5 facial palsy \\
\hline Zhang et al., 2000 & Epidermoid & 30 & NA & NA & NA \\
\hline Schroeder et al., $2004 \dagger$ & Epidermoid & 8 & $3(37) \S$ & $\mathrm{HL}$ in 1 case & Transient in 1 case \\
\hline Safavi-Abbasi et al., 2008 & Epidermoid & 11 & $7(64) \pi$ & No $\mathrm{HL}$ & 1 facial palsy \\
\hline Tuchman et al., 2014 & Epidermoid & 9 & $1(11)$ & No HL & No facial palsy \\
\hline
\end{tabular}

$\mathrm{HB}=$ House-Brackmann grading; $\mathrm{HL}$ = hearing loss; $\mathrm{HP}$ = hearing preservation; $\mathrm{NA}=$ not available; $\mathrm{NUH}$ = nonuseful hearing; $\mathrm{RS}=$ retrosigmoid approach.

* Only 106 cases in this study had postoperative MRI.

† The average tumor size in this study was $3.9 \mathrm{~cm}$ and hearing preservation was not a surgical goal. The cochlear nerve was anatomically preserved only in 1 case; the main focus of this study was the evaluation of the endoscope in early identification of the facial nerve in large vestibular schwannomas.

‡ Facial nerve functional status in these studies was measured only in the early postoperative period.

$\S$ In this study total removal is of the tumor content, and total capsule removal was not a surgical goal.

IT Total capsule removal was not achieved in any of the cases of this study.

eral side of the brainstem. In addition, because of the texture of the tumor, hidden pieces are easily removed with the endoscope, and the freehand technique and tandem view allows for the cautious microdissection necessary for dissection of the capsule (Video 3). Finally, because postoperative MRI does not clearly show the residual tumor capsule, we believe that the endoscopic view is the best for evaluating the extent of resection.

Komotar et al. ${ }^{26}$ has noted that endoscopic-assisted surgery is valuable in chordoma surgery, even where purely endonasal endoscopic surgery is often used in their review. However, we did not identify any reports of an endoscopicassisted open skull-base approach for chordomas as used in the present series. Chordomas tend to spread in the basal bones and typically cross the midline; thus, extending the posterior fossa approach with the endoscope is very useful. The highly magnified, well-illuminated picture provided by the endoscope helps the surgeon to follow diseased bone through the basal bone and to the contralateral skull base. However, in our series, while the endoscope was useful in chordoma resection, its assessment of the extent of resection of chordomas was less beneficial than in other pathologies. This difficulty was due to lesions extending deep inside the bone, and islands of tumor may frequently be covered by seemingly normal-appearing bone.

\section{Conclusions}

The literature has historically emphasized the use of the endoscope in minimally invasive techniques. In the present study, we emphasize its significant role in standard and expanded skull-base surgery. The use of the endoscope improved access to a variety of skull-base tumors and was effective in expanding the standard approaches into additional intracranial compartments. It also increased the surgeon's ability to evaluate the extent of resection intraoperatively. Most importantly, it improved the ability to achieve additional safe tumor resection, which may be considered the greatest means of reducing longterm patient morbidity. To minimize the shortcomings of endoscopic-assisted surgery, we describe our technique of simultaneous viewing.

\section{Acknowledgment}

We thank Julie Yamamoto for her editorial assistance.

\section{References}

1. Abolfotoh M, Dunn IF, Al-Mefty O: Transmastoid retrosigmoid approach to the cerebellopontine angle: surgical technique. Neurosurgery 73 (1 Suppl Operative):ons16-ons23, 2013

2. Al-Mefty O, Kadri PA, Hasan DM, Isolan GR, Pravdenkova S: Anterior clivectomy: surgical technique and clinical applications. J Neurosurg 109:783-793, 2008

3. Al-Mefty O, Pravdenkova S, Gragnaniello C: A technical note on endonasal combined microscopic endoscopic with free head navigation technique of removal of pituitary adenomas. Neurosurg Rev 33:243-249, 2010

4. Betka J, Chovanec M, Zverina E, Profant O, Lukes P, Skrivan $\mathrm{J}$, et al: Minimally invasive endoscopic and endoscopy-assisted microsurgery of vestibular schwannoma, in Iancu C (ed): Advances in Endoscopic Surgery. Rijeka, Croatia: InTech, 2011, pp 191-216

5. Broggi M, Acerbi F, Ferroli P, Tringali G, Schiariti M, Broggi G: Microvascular decompression for neurovascular conflicts in the cerebello-pontine angle: which role for endoscopy? Acta Neurochir (Wien) 155:1709-1716, 2013 
6. Cappabianca P, Cavallo LM, Esposito F, de Divitiis E, Tschabitscher M: Endoscopic examination of the cerebellar pontine angle. Clin Neurol Neurosurg 104:387-391, 2002

7. Chaynes P, Deguine O, Moscovici J, Fraysse B, Becue J, Lazorthes Y: Endoscopic anatomy of the cerebellopontine angle: a study in cadaver brains. Neurosurg Focus 5(3):E8, 1998

8. Chovanec M, Zvěřina E, Profant O, Skřivan J, Cakrt O, Lisý $\mathrm{J}$, et al: Impact of video-endoscopy on the results of retrosigmoid-transmeatal microsurgery of vestibular schwannoma: prospective study. Eur Arch Otorhinolaryngol 270:12771284,2013

9. Chowdhury FH, Haque MR: Endoscopic assisted microsurgical removal of cerebello-pontine angle and prepontine epidermoid. J Neurosci Rural Pract 3:414-419, 2012

10. Colpan ME, Sekerci Z, Cakmakci E, Donmez T, Oral N, Mogul DJ: Virtual endoscope-assisted intracranial aneurysm surgery: evaluation of fifty-eight surgical cases. Minim Invasive Neurosurg 50:27-32, 2007

11. de Divitiis O, Cavallo LM, Dal Fabbro M, Elefante A, Cappabianca P: Freehand dynamic endoscopic resection of an epidermoid tumor of the cerebellopontine angle: technical case report. Neurosurgery 61 (5 Suppl 2):E239-E240, 2007

12. Ebner FH, Koerbel A, Roser F, Hirt B, Tatagiba M: Microsurgical and endoscopic anatomy of the retrosigmoid intradural suprameatal approach to lesions extending from the posterior fossa to the central skull base. Skull Base 19:319-323, 2009

13. El-Garem HF, Badr-El-Dine M, Talaat AM, Magnan J: Endoscopy as a tool in minimally invasive trigeminal neuralgia surgery. Otol Neurotol 23:132-135, 2002

14. Fukushima T: Endoscopy of Meckel's cave, cisterna magna, and cerebellopontine angle. Technical note. J Neurosurg 48:302-306, 1978

15. Gerganov VM, Giordano M, Herold C, Samii A, Samii M: An electrophysiological study on the safety of the endoscopeassisted microsurgical removal of vestibular schwannomas. Eur J Surg Oncol 36:422-427, 2010

16. Gerganov VM, Romansky KV, Bussarsky VA, Noutchev LT, Iliev IN: Endoscope-assisted microsurgery of large vestibular schwannomas. Minim Invasive Neurosurg 48:39-43, 2005

17. Göksu N, Bayazit Y, Kemaloğlu Y: Endoscopy of the posterior fossa and dissection of acoustic neuroma. J Neurosurg 91:776-780, 1999

18. Göksu N, Yilmaz M, Bayramoglu I, Aydil U, Bayazit YA: Evaluation of the results of endoscope-assisted acoustic neuroma surgery through posterior fossa approach. ORL J Otorhinolaryngol Relat Spec 67:87-91, 2005

19. Grotenhuis JA: The use of the endoscope in microvascular decompression surgery. Operat Tech Neurosurg 4:162-165, 2001

20. Hori T, Maruyama T, Chernov M: Clinical experience with endoscope-controlled removal of intrameatal vestibular schwannomas, in Kanno T, Kato T (eds): Minimally Invasive Neurosurgery and Neurotraumatology. Tokyo: Springer, 2010, pp 1760-1802

21. Iacoangeli M, Salvinelli F, Di Rienzo A, Gladi M, Alvaro L, Greco F, et al: Microsurgical endoscopy-assisted presigmoid retrolabyrinthine approach as a minimally invasive surgical option for the treatment of medium to large vestibular schwannomas. Acta Neurochir (Wien) 155:663-670, 2013

22. Jarrahy R, Berci G, Shahinian HK: Endoscope-assisted microvascular decompression of the trigeminal nerve. Otolaryngol Head Neck Surg 123:218-223, 2000

23. Jennings CR, O’Donoghue GM: Posterior fossa endoscopy. J Laryngol Otol 112:227-229, 1998

24. Kane AJ, Sughrue ME, Rutkowski MJ, Berger MS, McDermott MW, Parsa AT: Clinical and surgical considerations for cerebellopontine angle meningiomas. J Clin Neurosci 18:755-759, 2011
25. King WA, Wackym PA: Endoscope-assisted surgery for acoustic neuromas (vestibular schwannomas): early experience using the rigid Hopkins telescope. Neurosurgery 44:1095-1102, 1999

26. Komotar RJ, Starke RM, Raper DM, Anand VK, Schwartz TH: The endoscope-assisted ventral approach compared with open microscope-assisted surgery for clival chordomas. World Neurosurg 76:318-327, 2011

27. Kumon Y, Kohno S, Ohue S, Watanabe H, Inoue A, Iwata $\mathrm{S}$, et al: Usefulness of endoscope-assisted microsurgery for removal of vestibular schwannomas. J Neurol Surg B Skull Base 73:42-47, 2012

28. Lang SS, Chen HI, Lee JY: Endoscopic microvascular decompression: a stepwise operative technique. ORL J Otorhinolaryngol Relat Spec 74:293-298, 2012

29. Little AS, Almefty KK, Spetzler RF: Endoscopic surgery of the posterior fossa: strengths and limitations. World Neurosurg 82:322-324, 2014

30. Magnan J, Barbieri M, Mora R, Murphy S, Meller R, Bruzzo $\mathrm{M}$, et al: Retrosigmoid approach for small and medium-sized acoustic neuromas. Otol Neurotol 23:141-145, 2002

31. Miyazaki H, Deveze A, Magnan J: Neuro-otologic surgery through minimally invasive retrosigmoid approach: endoscope assisted microvascular decompression, vestibular neurotomy, and tumor removal. Laryngoscope 115:1612-1617, 2005

32. Nishiyama Y, Kinouchi H, Horikoshi T: Surgery on intracranial aneurysms under simultaneous microscopic and endoscopic monitoring. Clin Neurosurg 58:84-92, 2011

33. O'Donoghue GM, O'Flynn P: Endoscopic anatomy of the cerebellopontine angle. Am J Otol 14:122-125, 1993

34. Peris-Celda M, Da Roz L, Monroy-Sosa A, Morishita T, Rhoton AL Jr: Surgical anatomy of endoscope-assisted approaches to common aneurysm sites. Neurosurgery 10 (1 Suppl 1):121-144, 2014

35. Rak R, Sekhar LN, Stimac D, Hechl P: Endoscope-assisted microsurgery for microvascular compression syndromes. Neurosurgery 54:876-883, 2004

36. Rhoton AL Jr: Aneurysms. Neurosurgery 51 (4 Suppl):S121-S158, 2002

37. Safain MG, Dent WC, Heilman CB: An endoscopic assisted retrosigmoid approach to the cerebello-pontine angle for resection of an epidermoid cyst. Neurosurg Focus 36 (1 Suppl):Video 16, 2014

38. Safavi-Abbasi S, Di Rocco F, Bambakidis N, Talley MC, Gharabaghi A, Luedemann W, et al: Has management of epidermoid tumors of the cerebellopontine angle improved? A surgical synopsis of the past and present. Skull Base 18:85-98, 2008

39. Schroeder HW, Hickmann AK, Baldauf J: Endoscope-assisted microsurgical resection of skull base meningiomas. Neurosurg Rev 34:441-455, 2011

40. Schroeder HW, Oertel J, Gaab MR: Endoscope-assisted microsurgical resection of epidermoid tumors of the cerebellopontine angle. J Neurosurg 101:227-232, 2004

41. Seki Y, Umezu H, Usui M, Tsumanuma T, Nakatate K: "Picture-in-picture" endoscopic images in the microscope. Neurosurg Focus 6(4):E10, 1999

42. Takaishi Y, Yamashita H, Tamaki N: Cadaveric and clinical study of endoscope-assisted microneurosurgery for cerebral aneurysms using angle-type rigid endoscope. Kobe J Med Sci 48:1-11, 2002

43. Takemura Y, Inoue T, Morishita T, Rhoton AL Jr: Comparison of microscopic and endoscopic approaches to the cerebellopontine angle. World Neurosurg 82:427-441, 2014

44. Tatagiba M, Matthies C, Samii M: Microendoscopy of the internal auditory canal in vestibular schwannoma surgery. Neurosurgery 38:737-740, 1996

45. Tuchman A, Platt A, Winer J, Pham M, Giannotta S, Zada 
G: Endoscopic-assisted resection of intracranial epidermoid tumors. World Neurosurg 82:450-454, 2014

46. Xia Y, Li XP, Han DM, Zheng J, Long HS, Shi JF: Anatomic structural study of cerebellopontine angle via endoscope. Chin Med J (Engl) 120:1836-1839, 2007

47. Yuguang L, Chengyuan W, Meng L, Shugan Z, Wandong S, Gang L, et al: Neuroendoscopic anatomy and surgery of the cerebellopontine angle. J Clin Neurosci 12:256-260, 2005

48. Zhang Y, Wang C, Liu P, Gao X: Clinical application of neuroendoscopic techniques. Stereotact Funct Neurosurg 75:133-141, 2000

\section{Author Contributions}

Conception and design: Al-Mefty, Abolfotoh, Dunn. Acquisition of data: Al-Mefty, Abolfotoh, Bi, Hong, Boskovitz, Dunn. Analysis and interpretation of data: Abolfotoh, Bi, Hong. Drafting the article: all authors. Critically revising the article: all authors. Reviewed submitted version of manuscript: all authors. Approved the final version of the manuscript on behalf of all authors: Al-Mefty. Statistical analysis: Abolfotoh, Bi. Administrative/ technical/material support: Al-Mefty, Dunn. Study supervision: Al-Mefty.

\section{Supplemental Information \\ Previous Publication}

Portions of this work were presented as a digital poster at the
2013 AANS annual meeting and at the 2014 CNS annual meeting.

\section{Videos}

Video 1, Media Player. http://mfile.akamai.com/21490/wmv/ digitalwbc.download.akamai.com/21492/wm.digitalsource-naregional/jns14-1465_video_1.asx.

Video 1, Quicktime. http://mfile.akamai.com/21488/mov/ digitalwbc.download.akamai.com/21492/qt.digitalsource-global/ jns14-1465_video_1.mov.

Video 2, Media Player. http://mfile.akamai.com/21490/wmv/ digitalwbc.download.akamai.com/21492/wm.digitalsource-naregional/jns14-1465_video_2.asx.

Video 2, Quicktime. http://mfile.akamai.com/21488/mov/ digitalwbc.download.akamai.com/21492/qt.digitalsource-global/ jns14-1465_video_2.mov.

Video 3, Media Player. http://mfile.akamai.com/21490/wmv/ digitalwbc.download.akamai.com/21492/wm.digitalsource-naregional/jns14-1465_video_3.asx.

Video 3, Quicktime. http://mfile.akamai.com/21488/mov/ digitalwbc.download.akamai.com/21492/qt.digitalsource-global/ jns14-1465_video_3.mov.

\section{Correspondence}

Ossama Al-Mefty, Department of Neurosurgery, Brigham and Women's Hospital, 75 Francis St., Boston, MA 02115. email: oalmefty@partners.org. 